East African Medical Journal Vol. 80 No. 10 October 2003

IODINE CONCENTRATION IN SALT AT HOUSEHOLD AND RETAIL SHOP LEVELS IN SHEBE TOWN, SOUTH WEST ETHIOPIA

L. Takele, BSc, Laboratory Technologist, South People Nations and Nationalities People's Regional Health Bureau, T. Belachew, MD, MSc, DLSHTM, Assistant Professor, Community Health Programme and T. Bekele, BSc, MSc, Lecturer, School of Medical Laboratory Technology, Jimma University, P.O. Box 1104, Jimma, Ethiopia

Request for reprints to: Dr. T. Belachew, Community Health Programme, Jimma University, P.O. Box 1104, Jimma, Ethiopia

\title{
IODINE CONCENTRATION IN SALT AT HOUSEHOLD AND RETAIL SHOP LEVELS IN SHEBE TOWN, SOUTH WEST ETHIOPIA
}

\section{TAKELE, T. BELACHEW and T. BEKELE}

\begin{abstract}
Objectives: To determine the level of iodine in the salt at the retail shop and consumption levels and assess the knowledge, attitude and practice (KAP) of food caterers and shopkeepers about iodized salt and iodine deficiency disorders (IDD).

Design: Cross-sectional community based.

Setting: Retail shops and households in Shebe town-Jimma zone, southwest Oromiya region. Subjects: Thirty three shopkeepers and 299 food caterers of households in Shebe town.

Results: The iodine content of household salt samples ranged, from 0-75 PPM and that of the shop samples ranged from 0. 1-75PPM. Eighty one per cent of household salt samples and 82 $\%$ of shop salt samples have iodine levels below the minimum standard set by the Quality and Standard Authority of Ethiopia. Knowledge about iodized salt was fairly lower for food caterers $(\mathbf{2 1 \%})$ than shopkeepers $(\mathbf{5 7 . 6 \%})$. More $(\mathbf{8 0} \%)$ of shopkeepers have favourable attitude than household food caterers $(\mathbf{5 0 . 6 \%})$. Improper practices of food caterers related to iodized salt were found to be associated with female sex $(P<0.01)$, Amhara ethnicity $(P<$ 0.001), Orthodox religion $(P=0.008)$, literacy status $(p=0.04)$ and occupation $(P=0.01)$. Good knowledge, about iodized salt was significantly associated with favourable attitude among food caterers $(P<0$. 001).

Conclusion: This study demonstrated that high proportions of residents in Shebe town were consuming inadequately iodized salt. There is a marked loss of iodine from salt by the time it reaches to consumption level in that some households were found to use salt with zero iodine content, whereas, all salt samples collected from the shops have at least some iodine. Poor awareness about iodized salt among food caterers and even in shopkeepers was also disclosed in this study. Socio-demographic factors such as ethnicity, religion, sex, lower educational level of food caterers might have an influence on poor, household practices like exposure of salt to sunlight. Information, education and communication on the importance consuming iodized salt and its proper handling in the house and regular monitoring of the salt iodine level at consumer level is essential for elimination of IDD.
\end{abstract}

\section{INTRODUCTION}

The term iodine deficiency disorders (IDD) has been adopted to describe the spectrum of effects of iodine deficiency that include goiter, endemic creatinism psychomotor delays, and increased pre-and post-natal mortality $(1,2)$.

IDD remains a significant public health problem in many countries. Recent studies have shown that over 200 million people in the world are affected by the most visible symptom of iodine deficiency disorders(2). Globally, $30 \%$ of the world's population is affected by IDD and more than 150,000 million people are affected in Africa alone. In Ethiopia, one out of every 1000 is a cretin, and about 50,000 peri-natal deaths are occurring annually due to iodine deficiency disorders, $26 \%$ of the total population have goiter and $62 \%$ of the population is at risk of IDD according to national survey made by the previous Ethiopian Nutrition Institute(3). In some pocket areas of the country, the prevalence of goiter is found to be $50-95 \%$ (WHO considers that if the goiter rate is above 5\% in the population it is a public health problem). From the various surveys conducted in many parts of Ethiopia, IDD has become one of the biggest public health concerns. Various surveys of goiter prevalence showed that it is getting hold of the upper hand of micronutrient deficiency with particular predilection to the highlands and inland areas with the prevalence ranging from $0.4 \%$ to $63 \%$. The number of creatins was estimated to be $37,000(4)$.

IDD can be eliminated in a cost effective way as it has been in most industrialised countries by adding iodine to universally consumed product, common salt. That means salt iodization to a level of 30 - 100 PPM with any iodine compound, usually in the form of potassium iodide (KI) or potassium iodate $\left(\mathrm{KIO}_{3}\right)(5,6)$. 
Consistent monitoring of iodine in salt at production, storage, sale and consumption level; and prevention of sale of non-iodated salt is vital components of salt iodization programme that should be adjusted to meet local conditions and requirements. The information generated by monitoring mechanism should directly be linked to decision-making, and there should be a feed back system allowing necessary changes to be made(5). Therefore, monitoring salt iodization is a useful first step in tracking process towards meeting the goal of IDD elimination.

Universal salt iodization (USI) is the most widely practiced intervention in eliminating iodine deficiency disorders (IDDs). Salt iodine testing is an important "process" indicator for monitoring progress towards USI(7). Although considerable success in eliminating or reducing endemic goiter has been achieved through national salt iodization programmes and even in some with mandatory iodization programmes of household salt, IDD remains to be a problem(8).

Further extension of IDD control programme is likely and preparations are underway in many countries. In Africa, 36 countries had data on the magnitude of problem of which 14 countries carried out surveys since 1987 in Algeria, Congo, Kenya, Malawi, Mali, Tanzania, Zaire and Ethiopia(2).

A study conducted in goiter endemic districts in Northern India to assess the iodine content of salt at household and retail levels found out that $80 \%$ of salt samples contain less than the minimum recommended level by the government $(15 \mathrm{mg} / \mathrm{kg})$ despite an official ban on the entry of un-iodized salt since October 1986. It was also reported that there was no significant difference in the iodine content of samples from households and shops. Iodine content of packed salt was higher than loose bags collected from shops. This study implicated an urgent need for proper monitoring of iodine content at production, distribution, storage, wholesale and retail level in order to ensure the minimum recommended level at the households(5).

Another study carried out in South Africa to evaluate the effectiveness of mandatory iodization of salt after one year indicated that favourable changes were observed on the process indicator between baseline and follow-up. There was an increase in the proportion of households that used iodized salt and an increase in iodine concentration of table salt. Even if the iodine content of retail samples increased to a mean of $25 \mu \mathrm{g} / \mathrm{g}$ at follow up one year later it is somewhat below the revised legal requirement, $40-60 \mu \mathrm{g} / \mathrm{g}(9)$. But, still the salt iodine content was below the legal requirement indicating that only mandatory salt iodization is not a guarantee for consumption of acceptable level of iodine by the households.

In 1987 analysis of 50 specimens of salt from across the country in Guatemala found that $86 \%$ had a concentration below 60PPM, the legal criterion at that time(10). Studies in Tanzania indicated that after iodization machinery was installed in 1992 and legislation for iodization of salt was enacted in 1996, the proportion of households consuming iodated salt in the highly endemic areas steadily rose from zero before the programme to over $90 \%$ in some areas(11).

In order to prevent IDD, universal salt iodization (USI) programme was launched in Ethiopia earlier(1). The Quality and Standards Authority of Ethiopia, has set the iodine level to be 60-80 PPM as potassium iodate, after making allowance for losses of iodine during storage and distribution. In Ethiopia, the average consumption of salt per capita per day is 10 grams and salt with iodine content of $60 \mathrm{mg} / \mathrm{kg}$ would therefore satisfy the recommended daily requirement of $150 \mu \mathrm{g}$ of iodine per person to prevent IDD(1). But, there was no data that indicates the iodine level of salt both at the retail and consumption levels. Even most studies done outside the country did not try to see the knowledge, attitude and practice (KAP) of shopkeepers and household food caterers about iodized salt.

Therefore, this study was conducted to determine salt iodine level as an important process' indicator and related factors that affect the loss of iodine content at consumption and retail levels in relation to the KAP of consumers and shopkeepers (retailers) about iodized salt and IDD. The results of this study could also be used as baseline for a further study and intervention.

\section{MATERIALS AND METHODS}

The study was conducted in Shebe town in Seka Chekorsa district of Jimma zonal administration, Oromiya regional state. Shebe is located $55 \mathrm{~km}$ southwest of Jimma town at an altitude of 1580-2560 meters above sea level and has a total projected population of 6075 and 1113 households. The overall goiter prevalence in school children (6-15 years) in the woreda was $64.1 \%(12)$. This figure indicates the severity of IDD endemia (TGR $>30 \%$ ) in the woreda as well as in the Shebe town. In the town, there is one project, MICAH, concerned about micronutrients deficiency especially on elimination of IDD, iron deficiency and vitamin A deficiency. The project has been implementing some intervention measures against micronutrients deficiencies like vitamin A and iron since a few years ago. But there was no intervention on IDD in the area. This study was conducted between January 1st and February 12 th 2001.

A cross-sectional study design was employed, as it is appropriate to determine iodine content of the salt samples and KAP both at the retail shop and household consumption levels. Since there is no previous study done regarding prevalence of iodated salt users, expected population proportion (P) was assummed to be $50 \%$, and $95 \%$ confidence interval was employed to get maximum sample size. Using a published formula, a final sample size of 299 households and all the 33 shopkeepers in the town were included in the study. A systematic random sampling technique was employed to select households for taking salt sample and interview of food caterers. The sampling unit was household and every 4th household was taken for the consumption level study after selection of the first household using a lottery method based on the house numbers. A total of 384 salt samples were collected from all shops and households by data collector as follows: The salt samples were collected from the top, middle, and bottom of the pack (bag) 
using moisture free, clean plastic container with cover. The samples were labeled with the following information during collection: Date of sampling, source of salt and Batch number and tested using Single Solution Kit (SSK) for iodates:

Principle: Iodate in the salt oxidizes iodine added to the salt in the presence of free $\mathrm{H}+$ and gives free iodine. The free iodine turns starch into light blue to dark colour.

Procedure: As described on the kit, small amount of salt was placed on saucer and moistened with two drops of test reagent. The presence of iodine in the salt was recorded by observing the immediate turn of its colour light blue to dark and the persistence of this colour for several minutes. Colour charts on the kit corresponding to values 0.1-25 PPM, 25.1-50PPM, 50.1 - 75PPM and 75.1-100PPM were used to estimate iodine level in salt sample. A post basic degree medical laboratory student performed the test and collected data on socio-demographic variables like age, sex, ethnicity, religion, and educational level, occupation and knowledge, attitude and practice (KAP) of both household food caterers and shopkeepers using a structured questionnaire. Knowledge was assessed by asking a range of questions about IDD, iodized salt and marking the correct answers of subjects out of a hundred. Knowledge scores $50 \%$ or less were labeled to be "poor knowledge" knowledge scores greater than $50 \%$ were labeled to be good knowledge".

To assess attitude towards iodized salt, likert scale was constructed by presenting respondents with a series of negative and positive statements that reflect different aspects of underlying attitude in a variety of ways. Attitude statements had five possible responses. The responses were labeled "favourable" or "unfavourable" as follows; For positive statements, responses including Strongly agree and agree were labeled as "favourable" and disagree, strongly disagree and uncertain were labeled as "unfavorable". For negative statements, those who responded "strongly agree", "agree" and uncertain were labeled as "unfavourable" and strongly disagree, disagree were labeled to have "favourable" response. Marking the total attitude score out of a hundred, those with score of greater than $50 \%$ were rated to have favourable attitude and those with a score below $50 \%$ as unfavourable attitude.

Subjects with any single practice that might result in the reduction of salt iodine content were labeled to have improper practice and those without such practices were labeled to have proper practices.

Data were cleaned, edited and entered into a computer and analysed using SPSS for windows version 7.5. The level of significance, was set at 5\%. Chi-square test and logistic regression analysis were performed to see the association of sociodemographic variables with household practices that affect salt iodine level. Precise evaluation of analytical check on test kit was done before the study. The questionnaire was pre-tested and revised for the main study. Informed consent was obtained both from the shopkeepers and heads of the households in the community before data collection.

\section{RESULTS}

A total of 332 subjects (299 food caterers and 33 shopkeepers) aged 15-49years were included in the study. Nineteen $(6.4 \%)$ of food caterers and $22(66.7 \%)$ of shopkeepers were males, respectively. The predominant religion in both shopkeepers and household food caterers were Muslims accounting for $66.7 \%$ and $47.8 \%$, respectively and the rest were Christians. One hundred and fifty two $(50.8 \%)$ of the food caterers were illiterate and $118(54.5 \%)$ of the shopkeepers had attended elementary school. The most frequent ethnicity in both study populations was Oromo accounting for $155(51.8 \%)$ and $10(30.3 \%)$ in the household food caterers and shopkeepers, respectively. The rest ethnicities in both groups included Amhara, Gurage, and Kefa. Most of the heads of the households were daily labourers; $79(26.4 \%)$ followed by government employees $75(25.1 \%)$, merchants 63(21.1\%), farmers; 55(18.4\%), housewifes $27(9.0 \%)$. Larger proportions of households were using iodized salt 255(92.7\%) and the rest 20(7.3\%) used non-iodized salt.

Among household samples, iodine concentration varied from 0-75 PPM with a mean of 28.9 and standard deviation of $20.4(X \pm$ S.D) PPM. The most frequent value $116(42 \%)$ was found to be in the range of $0.1-25$ PPM. At least $20(7.3 \%)$ had no iodine content at all. More than 224 $(8.1 \%)$ had a concentration below 60PPM, the minimum Standard value set by the Quality and standards Authority of Ethiopia(13). Only 19\% mean (62.55PPM) value as 50.1-75PPM was found in the standard level (60-80ppm), (Figure 1). Iodine concentration in the retail shop salt samples ranged from 0.11-75 PPM with a mean value of 34.52 and standard deviation of 17.40 PPM, which was larger than household samples. The least proportion $10(30.5 \%)$ and largest proportion $17(51.5 \%)$ were found in the range of 0. 1-25PPM and 21.11-50 PPM, respectively (Figure 1). Nearly similar proportions; six (18.2\%) of retail shop samples were found in the highest range of $50.1-75 \mathrm{ppm}$. The variation of salt iodine level between household and retail samples gets wider when it comes to the lower ranges of iodine level in that the household sample had lower values as compared to the retail.

Almost half of the food caterers $148(49.5 \%)$ had proper practice related to iodized salt, they usually add salt late at the end of cooking while nearly equal proportion $151(50.5 \%)$ add salt in the early beginning and in the middle of cooking which is improper practice (Table 1). Most $(73.9 \%)$ of the food caterers exposed their salt to sunlight while the remaining $78(26.1 \%)$ did not. The majority (93\%) of salt containers in the households had cover but the remaining 21(7\%) did not. Almost all (99.3\%) stored their salt in dry places while two $(0.7 \%)$ food caterers stored in moist area (Table 1).

\section{Figure 1}

\section{Iodine level in the household and retail shop salt samples}

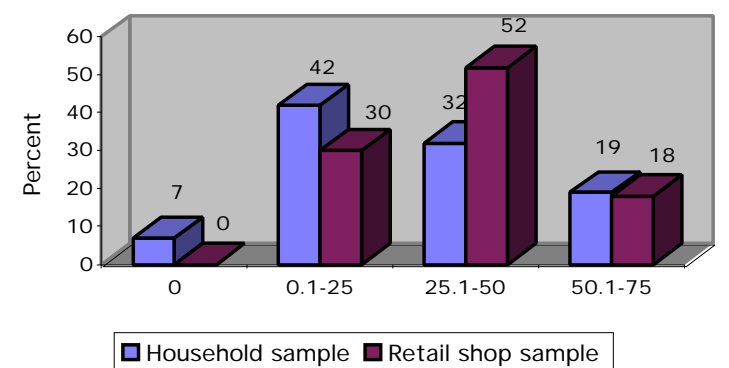

PPM (Microgram/Gram of salt) 


\section{Table 1}

Practices of food caterers in handling iodized salt at household level

\begin{tabular}{lcc}
\hline Household practices of food caterers & No. & $\%$ \\
\hline Time salt is added during food cooking & & \\
Early and at the middle of cooking & 151 & $(50.5)$ \\
Late at the end of cooking & 148 & $(49.5)$ \\
Total & 299 & $(100)$ \\
Sunlight exposure of salt & & \\
Yes & 221 & $(73.9)$ \\
No & 78 & $(26.1)$ \\
Total & 299 & $(100)$ \\
Salt container & & \\
With cover & 278 & $(93)$ \\
Without cover & 21 & $(7)$ \\
Total & 299 & 100 \\
Salt storage place & & \\
Dry area & 297 & $(99.3)$ \\
Moist area & 2 & $(0.7)$ \\
\hline Total & 299 & $(100)$ \\
\hline
\end{tabular}

Knowledge about iodine deficiency was fairly low among food caterers compared to shopkeepers. Ninety six (32.1\%) of food caterers and 21(63.6\%) shopkeepers were able to identify at least one effect of iodine deficiency. Low proportion of food caterers $31(10 \%)$ as compared to $10(30.3 \%)$ of shopkeepers gave two or more effects of IDD. Some $85(28.4 \%)$ of food caterers and the majority of shopkeepers $31(93.9 \%)$ responded that they had ever heard of iodized salt. Only $70(23.4 \%)$ of food caterers and $19(57.6 \%)$ of shopkeepers knew that daily consumption of iodized salt could prevent iodine deficiency disorders (Table 2). Among food caterers the majority 324(78.5\%) had poor knowledge about iodized salt and the rest $65(21.7 \%)$ had good knowledge. In Contrast to this, larger proportion of shopkeepers $19(57.62 \%)$ had good knowledge while 14 (42.4\%) had poor knowledge. (Figure 2).

Out of 299 food caterers and 33 shopkeepers interviewed, $85(22.4 \%)$ of the food caterers and $31(93.9 \%)$ of the shopkeepers responded that they had heard of iodized salt and were asked about their attitude towards it. In general, most 25(80.6\%) shopkeepers had favourable attitude towards iodized salt as compared to household food caterers 43(50.6\%) (Figure 3).

Figure 2

Knowledge of shopkeepers and household food caterers about iodized salt and IDD

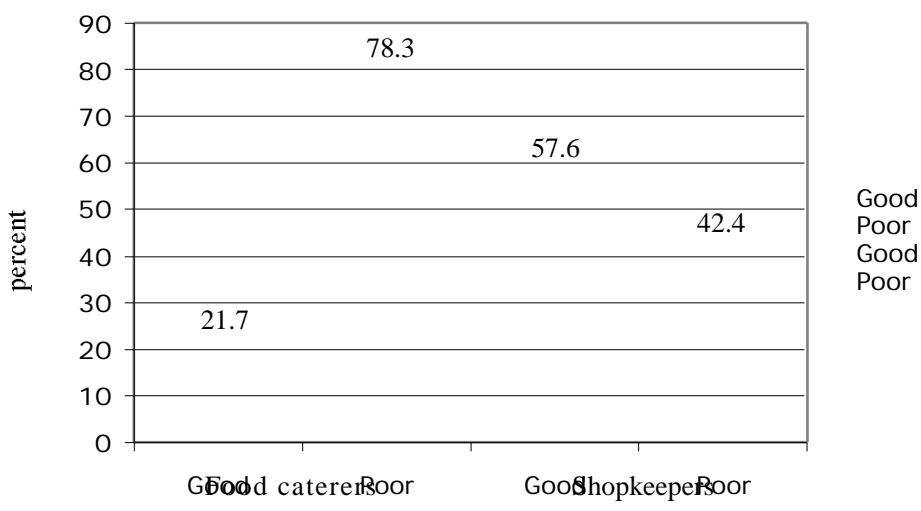

Table 2

Knowledge of household food caterers and shopkeepers about iodized salt

\begin{tabular}{lccccc}
\hline Knowledge & \multicolumn{2}{c}{ Food caterers } & \multicolumn{2}{c}{ Shopkeepers } \\
\hline \multirow{2}{*}{$\begin{array}{l}\text { Knows effects of iodine deficiency } \\
\text { At least one }\end{array}$} & No. & $\%$ & No. & $\%$ \\
& Yes & 96 & 32.1 & & \\
\multicolumn{1}{c}{ Two or more } & No & 203 & 67.9 & 12 & 36.4 \\
& Total & 299 & 100 & 33 & 100 \\
& Yes & 30 & 10 & 10 & 30.3 \\
Heard about iodized salt & No & 269 & 90 & 22 & 69.7 \\
\multirow{2}{*}{ Knows that iodized salt prevents IDD } & Total & 299 & 100 & 33 & 100 \\
& Yes & 85 & 28.4 & 31 & 93.9 \\
& No & 214 & 71.6 & 2 & 6.1 \\
& Yotal & 299 & 100 & 33 & 100 \\
& No & 70 & 23.4 & 19 & 57.6 \\
& Total & 299 & 76.6 & 14 & 42.4 \\
\end{tabular}


Figure 3

Attitude of household food caterers and shopkeepers towards iodized salt

Shopkeepers Food Caterers

Improper practice (exposure of salt to sunlight) was significantly associated with female $\operatorname{sex}(\mathrm{P}<0.01)$, ethnicity $(\mathrm{P}=0.02)$, occupation $(\mathrm{P}=0.01)$ (Table 4$)$. Improper practice of adding salt during cooking was significantly associated with sex $(\mathrm{P}=0.01)$, ethnicity $(\mathrm{p}=0.02)$ and occupation $(\mathrm{P}=0.01)$ (Table 5).

\section{DISCUSSION}

Five years after the implementation of a national programme for the control and elimination of iodine deficiency disorders through universal salt iodization, there was a change in the process indicator on iodine status, which was evident from the proportion of households that used iodized salt $(92.7 \%)$ and proportion of iodized salt in samples collected from shops $(100 \%)$ in Shebe town.
The baseline national survey that was in 1996 just at the start of national programme during a multiple indicator survey in order to assess the proportion of households in the country indicated that only $0.2 \%$ of households were consuming iodized salt. Then after an agreement with the Eritrean micronutrient committee to follow up the case of exported iodized salt to Ethiopia from Eritrea was sharply on the rise until it got to $68 \%$ from only $10 \%$ within five months time just before the Ethio-Eritrean border dispute(13). This is in line with the findings of the current study. The results of this study were also close to the results of a study conducted in Tanzania, which indicated that after iodization machinery was installed in 1992 and legislation for iodation of salt was enacted in 1996, the proportion of households consuming iodized salt in the highly endemic areas steadily rose from zero before the programme to over $90 \%$ in some areas(11). The level of iodization should take into account the degree of iodine deficiency; the mean salt intake and loss of iodine between production and consumption sites (14). With this aim the Quality and Standards Authority of Ethiopia, has set the iodine level as 60-80 PPM as potassium iodate(13).

Although the proportion of households consuming iodized salt is increasing after the start of a national programme, the current study indicated that there is an inadequate iodine concentration of salt samples within the required range. More than $81.5 \%$ of the salt samples in the study area were below 60PPM the minimum range of the standard. This finding is similar to that of the study done in South Africa in which changes such as the increase in the proportion of households $(82.2 \%)$ that used iodized salt, the increase in the iodine concentration of table salt in the area were observed in the process indicators between baseline and follow up. But, they were using salt iodized below the legal requirement of 40-60PPM(9).

Table 3

Scores of responses of shopkeepers and food caterers to attitude statements

\begin{tabular}{|c|c|c|c|c|c|c|c|c|c|c|}
\hline & \multicolumn{5}{|c|}{ Responses of household food caterers } & \multicolumn{5}{|c|}{ Responses of shopkeepers } \\
\hline & *S. Agree & Agree & Uncertain & Disagree & S.Disagree & Agree & Agree & Uncertain & \multicolumn{2}{|c|}{ Disagree*S.Disagree } \\
\hline \multicolumn{11}{|l|}{ Attitude Statement } \\
\hline & No. $(\%)$ & No. $(\%)$ & No. $(\%)$ & No. $(\%)$ & No. $(\%)$ & No. $(\%)$ & No. $(\%)$ & No. $(\%)$ & No. $(\%)$ & No. $(\%)$ \\
\hline $\begin{array}{l}\text { 1. I believe that food prepared with } \\
\text { iodized salt tastes less delicious } \\
\text { than non-iodized salt does }\end{array}$ & $2(2.4)$ & $19(24.4)$ & $37(43.5)$ & $27(31.8)$ & - & $8(25.9)$ & $8(25.8)$ & $6(19.4)$ & $5(16.1)$ & $4(12.9)$ \\
\hline $\begin{array}{l}\text { 2. I believe that iodized salt incurs } \\
\text { more cost than its benefits }\end{array}$ & $8(9.4)$ & $15(17.6)$ & $25(29.4)$ & $33(38.8)$ & $4(4.7)$ & $4(12.9)$ & $8(25.8)$ & $7(22.6)$ & $10(32.3)$ & $2(6.5)$ \\
\hline $\begin{array}{l}\text { 3. I believe that giving iodized salt } \\
\text { to small children in advisable }\end{array}$ & $18(21.2)$ & $55(64.7)$ & $9(10.6)$ & $3(3.5)$ & - & $2(6.5)$ & $25(80.6)$ & $2(6.5)$ & $2(6.5)$ & - \\
\hline $\begin{array}{l}\text { 4. I believe that iodized salt shoul d } \\
\text { be handled in the store, household etc } \\
\text { with great care than non-iodized salt }\end{array}$ & $3(3.5)$ & $45(52.9)$ & $25(29.4)$ & $10(11.8)$ & $2(2.4)$ & $8(25.8)$ & $20(64.5)$ & $3(9.7)$ & - & - \\
\hline $\begin{array}{l}\text { 5. I believe in advising my family } \\
\text { members to use iodized salt }\end{array}$ & $19(22.4)$ & $60(70.6)$ & $4(4.7)$ & $2(2.4)$ & - & $10(32.2)$ & $19(61.3)$ & $2(6.5)$ & - & - \\
\hline $\begin{array}{l}\text { 6. I believe in using iodized salt } \\
\text { than non-iodized salt }\end{array}$ & $37(43.5)$ & $41(48.2)$ & $2(2.4)$ & $5(5.9)$ & - & $4(12.9)$ & $23(74.2)$ & $4(12.9)$ & - & - \\
\hline
\end{tabular}

$*$ S. Agree $=$ Strongly agree, $*$ S. Disagree $=$ Strongly disagree 
Table 4

Sunlight exposure of salt by socio-demographic characteristics of food caterers

\begin{tabular}{|c|c|c|c|c|}
\hline \multirow{3}{*}{ Socio demographic characteristic } & \multicolumn{3}{|c|}{ Sunlight exposure of salt } & \\
\hline & \multirow{2}{*}{$\begin{array}{c}\text { Yes } \\
\text { No. }(\%)\end{array}$} & \multirow{2}{*}{$\begin{array}{c}\text { No } \\
\text { No. }(\%)\end{array}$} & \multicolumn{2}{|c|}{ P-value } \\
\hline & & & Univariate & Multivariate \\
\hline \multicolumn{5}{|l|}{ Age Group } \\
\hline $15-20$ & 41(13.7) & $13(4.3)$ & \multirow{7}{*}{0.02} & \multirow{7}{*}{0.74} \\
\hline 2125 & $44(14.7)$ & $14(4.7)$ & & \\
\hline $26-30$ & $50(16.7)$ & $27(9.0)$ & & \\
\hline $31-35$ & $17(5.7)$ & $8(2.7)$ & & \\
\hline $36-40$ & $26(8.7)$ & $8(2.7)$ & & \\
\hline $41-45$ & $19(6.4)$ & $4(1.3)$ & & \\
\hline $46-50$ & $24(8.0)$ & $4(1.3)$ & & \\
\hline \multicolumn{5}{|l|}{ Sex } \\
\hline Male & $3(15.8)$ & $16(84.2)$ & \multirow[b]{2}{*}{0.000} & \multirow[b]{2}{*}{0.01} \\
\hline Female & $218(77.9)$ & $62(22.1)$ & & \\
\hline \multicolumn{5}{|l|}{ Marital status } \\
\hline Married & $151(26.3)$ & $47(23.7)$ & \multirow{4}{*}{0.000} & \multirow{4}{*}{0.43} \\
\hline Single & $24(53.3)$ & $21(46.7)$ & & \\
\hline Divorced & $12(63.2)$ & $7(36.8)$ & & \\
\hline Widowed & $34(91.9)$ & $3(8.1)$ & & \\
\hline \multicolumn{5}{|l|}{ Religion } \\
\hline Muslims & $95(64.4)$ & $48(33.6)$ & \multirow{3}{*}{0.008} & \multirow{3}{*}{0.58} \\
\hline Orthodox & $96(83.5)$ & $19(16.5)$ & & \\
\hline Protestants & $30(73.2)$ & $11(16.8)$ & & \\
\hline \multicolumn{5}{|l|}{ Ethnicity } \\
\hline Oromo & $94(60.6)$ & $61(39.4)$ & \multirow{4}{*}{0.000} & \multirow{4}{*}{0.02} \\
\hline Amhara & $50(90.9)$ & $5(9.1)$ & & \\
\hline Kefa & $61(85.9)$ & $10(14.1)$ & & \\
\hline Garage & $16(88.9)$ & $2(11.1)$ & & \\
\hline \multicolumn{5}{|l|}{$\begin{array}{l}\text { Occupation of the head of } \\
\text { House hold }\end{array}$} \\
\hline Merchant & $50(79.4)$ & $13(20.6)$ & \multirow{5}{*}{0.003} & \multirow{5}{*}{0.01} \\
\hline Daily labourer & $58(73.4)$ & $21(26.6)$ & & \\
\hline Government employee & $45(60)$ & $30(40)$ & & \\
\hline House wife & $26(96.3)$ & $1(3.7)$ & & \\
\hline Farmer & $42(76.4)$ & $13(23.6)$ & & \\
\hline \multirow{4}{*}{$\begin{array}{l}\text { Educational level } \\
\text { Illiterate } \\
\text { Elementary School } \\
\text { Junior High school and 12+ }\end{array}$} & $113(74.3)$ & $39(25.7)$ & \multirow{4}{*}{0.002} & \multirow{4}{*}{0.34} \\
\hline & $47(79.7)$ & $12(20.3)$ & & \\
\hline & $54(78.3)$ & $15(21.7)$ & & \\
\hline & $7(36.8)$ & $12(63.2)$ & & \\
\hline
\end{tabular}

A similar finding was recorded in an endemic district of North India where $80 \%$ of salt samples contains less than the minimum recommended level by the government of $15 \mathrm{mg} / \mathrm{kg}$, despite an official ban on the entry of non-iodized salt since October 1982 (5). Another study within an extended Guatemalan community also showed that 50 salt samples $(86 \%)$ had a concentration below 60PPM, the legal criteria at that time(10).

As described in Table 3, proportions of salt samples, with lower ranges of iodine level were becoming larger for households than shops. A number of factors are known to influence stability of iodine in salt, such as the duration, storage condition, size of the crystals, impurities, moisture of the salt, ambient temperature, humidity and sunlight exposure(10). The presence of an inadequate amount of iodine in salt suggests an attempt to fortify the salt at the site of production. Inadequate quality control and insufficient government monitoring and enforcement probably play a role for inadequacy of most samples.

Demand creation of iodized salt and education is one of the plan of action in Ethiopia to prevent $\operatorname{IDD}(1)$. With a view to helping this, the present study had tried to assess knowledge, attitude, and practice of food caterers and shopkeepers about iodized salt.

Most $(93 \%)$ of salt containers had cover at household and the majority of food caterers (99.3\%) stored their salt in dry area. These good practices may not be due to care of iodized salt but to prevent the salt contamination and to keep them from moisture (Table 1). The study revealed that almost half $(50.5 \%)$ of food 
caterers had poor practices (they add salt early during cooking). Also more than half of them (73.9\%) expose their salt to sunlight (Table 1). This practice results in the loss of iodine from the salt (12). The majority of food caterers $(78.3 \%)$ had poor knowledge while among shopkeepers $(57.6 \%)$ had good knowledge. This may be because almost half of food caterers were illiterate and with less exposure to media than shopkeepers. Among food caterers almost half of them (50.6\%) had favourable attitude towards iodized salt while the majority of shopkeepers $(80.6 \%)$ had favourable attitude. The better knowledge that the shopkeepers have about iodized salt might have influenced their attitude.

\section{Table 5}

Salt adding practices of food caterers during cooking by socio-demographic characteristics

\begin{tabular}{|c|c|c|c|c|c|}
\hline \multicolumn{6}{|c|}{ Practice of adding salt during cooking } \\
\hline & Proper* & Improper** & Total & \multicolumn{2}{|l|}{ P-Value } \\
\hline & No. $(\%)$ & No. $(\%)$ & No. $(\%)$ & \multicolumn{2}{|c|}{ Univariate Multivariate } \\
\hline \multicolumn{6}{|l|}{ Sex } \\
\hline Male & $16(84.2)$ & $3(15.8)$ & 19(100) & & \\
\hline Female & $132(47.1)$ & $149(52.9)$ & $208(100)$ & 0.002 & 0.02 \\
\hline \multicolumn{6}{|l|}{ Age Group } \\
\hline $15-20$ & $34(63)$ & $20(37)$ & $54(100)$ & & \\
\hline $21-25$ & $22(37.8)$ & $36(62)$ & $58(100)$ & & \\
\hline $26-30$ & $42(54.5)$ & $35(45.5)$ & $77(100)$ & 0.013 & 0.46 \\
\hline $31-35$ & $15(60)$ & $10(40)$ & $25(100)$ & & \\
\hline $36-40$ & $18(52.9)$ & $16(47)$ & $34(100)$ & & \\
\hline $41-45$ & $10(43.5)$ & $13(56.5)$ & $23(100)$ & & \\
\hline $46-50$ & $7(25)$ & $21(75)$ & $28(100)$ & & \\
\hline \multicolumn{6}{|l|}{ Ethnicity } \\
\hline Oromo & $86(55.5)$ & $69(44.5)$ & $155(100)$ & & \\
\hline Gurage & $11(61.1)$ & $7(38.9)$ & $18(100)$ & & \\
\hline Amhara & $21(38.2)$ & $34(61.8)$ & $55(100)$ & 0.056 & 0.01 \\
\hline Kefa & $30(42.3)$ & $41(57.7)$ & $71(100)$ & & \\
\hline \multicolumn{6}{|l|}{ Religion } \\
\hline Muslims & $69(48.3)$ & $74(51.7)$ & $143(100)$ & 0.059 & 0.74 \\
\hline Orthodox & $56(48.7)$ & $59(51.3)$ & $115(100)$ & & \\
\hline Protestants & $23(56.1)$ & $18(43.9)$ & $41(100)$ & & \\
\hline \multicolumn{6}{|l|}{ Literacy state } \\
\hline Illiterate & $73(48.0)$ & $79(52.0)$ & $152(100)$ & & \\
\hline Grade 1-6 & 29(49.2) & $30(50.8)$ & $59(100)$ & 0.183 & 0.04 \\
\hline Grade $7-12$ & $32(46.4)$ & $37(53.6)$ & $69(100)$ & & \\
\hline $12+$ & $14(73.7)$ & $5(26.3)$ & $19(100)$ & & \\
\hline \multicolumn{6}{|l|}{ Marital status } \\
\hline Married & $95(48.0)$ & $103(52.0)$ & 198(100) & & \\
\hline Single & $30(66.7)$ & $15(33.3)$ & $45(100)$ & 0.00 & 0.13 \\
\hline Divorced & $15(78.9)$ & $4(21.1)$ & $19(100)$ & & \\
\hline Widowed & $8(21.6)$ & $29(78.4)$ & $37(100)$ & & \\
\hline \multicolumn{6}{|l|}{ Occupation } \\
\hline Merchant & $25(39.7)$ & $39(60.3)$ & $63(100)$ & & \\
\hline Farmer & $24(43.6)$ & $31(56.4)$ & $55(100)$ & 0.000 & 0.48 \\
\hline Government Employee & $38(50.7)$ & $37(49.3)$ & $75(100)$ & & \\
\hline Daily labourer & $42(53.2)$ & $37(46.8)$ & $79(100)$ & & \\
\hline House wife & $19(70.4)$ & $8(29.6)$ & $27(100)$ & & \\
\hline
\end{tabular}

*Proper $=$ Adding salt after cooking or at the end of cooking

**Improper=Adding salt at the beginning or in the middle of cooking 
Female sex was significantly associated with improper practice (exposure of salt to sunlight) compared to male $(\mathrm{P}=0.000)$. This may be due to the fact that mostly females are engaged with food preparation and are more exposed to different local or cultural practices than males

Orthodox religion and Amhara ethnicity were significantly associated with poor practices (sunlight exposure of salt among others $(\mathrm{P}<0.01)$, (Table 4$)$. This may be due to cultural practices including preparation of spices like pepper ("Berberre") evidenced in those who are orthodox Christians who probably might be Amhara.

Higher educational level was significantly associated with good practice (no habit of sunlight exposure of salt) $(\mathrm{P}=0.002)$. Better education may influence good practice, through better awareness about iodized salt. Even though good knowledge about iodized salt was significantly associated with favourable attitude $(\mathrm{P}=0.0091)$ both favourable attitude and good knowledge were not associated with good practices.

lodine deficiency is a major problem in Shebe town (12) and demands a control strategy, combining ongoing iodine supplementation and education. Iodized salt is usually the best approach to control of iodine deficiency disorders for most regions of the world. However, this study revealed that cultural and commercial factors can severely limit its impact. To be successful, control programme for iodine deficiency disorders also needs assessment of the salt trade, monitoring, education and occasional targeted interventions with iodized oil or other supplements.

\section{CONCLUSION}

This study demonstrated that high proportions of residents in Shebe town were consuming inadequately iodized salt. There was a discrepancy between iodine concentration of salt samples from households and shops in that some households were found to use non-iodized salt (salt with zero iodine content), whereas, all salt samples collected from the shops have at least some iodine. Poor awareness about iodized salt among food caterers and even in shopkeepers was also disclosed in this study.

Socio-demographic factors such as ethnicity, religion sex, lower educational level of food caterers might have an influence on poor household practices (e.g. exposure of salt for sunlight). There should be continuous monitoring of iodized salt at different points from production to household level in order to bring homogenous concentration of iodine in salt.
An information, education and communication should be conducted in the village about importance of consuming iodized salt and hence increasing the demand for it. Households should be instructed about importance of iodized salt and its proper handling in the house. Iodized salt should be made available at an affordable cost to the community and there should be a logo that enables the community to distinguish it from non-iodized salt.

\section{REFERENCES}

1 MOH-UNICEF. The miracle of iodated salt: Ethiopia's commitment of universal salt iodations (US1), circular. 1995; No.9.

2. Hofvander,Y.Goiter Among children in Ethiopia Highland: Effects of supply food with iodize salt. EMS 1970;8(2-4): 6879.

3. World vision Ethiopia, MICAH ACIDA- Funded micronutrient and health project, Addis Ababa.

4. Pandav, C.S., Arora, N.K., Krishnan, A. et al. Validation of Spot-testing kits to determine iodine content in salt. Bull WHO 2000; 78: 975-980.

5. Acclsen, second Report on world nutrition situation October 1992,

6. WHO Indicators for Accessing Iodine Deficiency Disorders and their control through salt iodization. Geneva: WHO/NUT/ 1994 (micronutrient series No.6).

7. WHO. Guiding for a National program for the control of Iodine Deficiency Disorders in the Eastern Mediterranean, 1988.

8. Jooste, P.L., Weight, M.J. and Lombard, C.I. Short-term effectiveness of mandatory iodine concentration, on the iodine and goiter status of school children with endemic goiter. Amer. J. Clin. Nutrition 2000; 71:75-80.

9. Taye, A. Prevalence of IDD and prominent factor on IDD in Shebe over, Seka Chekorsa woreda South Western Ethiopia, Bull. JIHS, 1997; 7:63.

10. Stewart C.H., Solomons N.et al. Salt iodine variation within an extended Guatemalan community: the failure of on futive assumptions. Bull. food and Nutrition. 1996; 71:258.

11. Kavisae, P. Can Africa meet the goal of eliminating iodine deficiency disorders by the year 2000; Bull. food and Nutrition 1996; 17:262.

12. Karmarkar, M.G., Panday, C.S. and Krishnamachari, K.A.V.R. Principle and procedure for iodine estimation: A laboratory manual. New Delhi, Indian Council of Medical Research, 1986.

13. MOH. Micro Nutrient deficiencies control program in Ethiopia - profile draft (unpublished document 2001).

14. Aboye and Urga, K. Laboratory Manual. Ethiopian Nutrition institute. Addis Ababa Ethiopia. (Unpublished document 1989).

15. Demaeyer, E.M. Lowe stein, F.W.,Thilly, C.H. The control of Endemic Goiter, Geneva, WHO, 1997.

16. Anandk, Wajih, S., Prakashset al. A role for non-governmental organizations in monitoring the iodine content of salt in northern India. Bull. WHO. 1995; 75:71-75. 